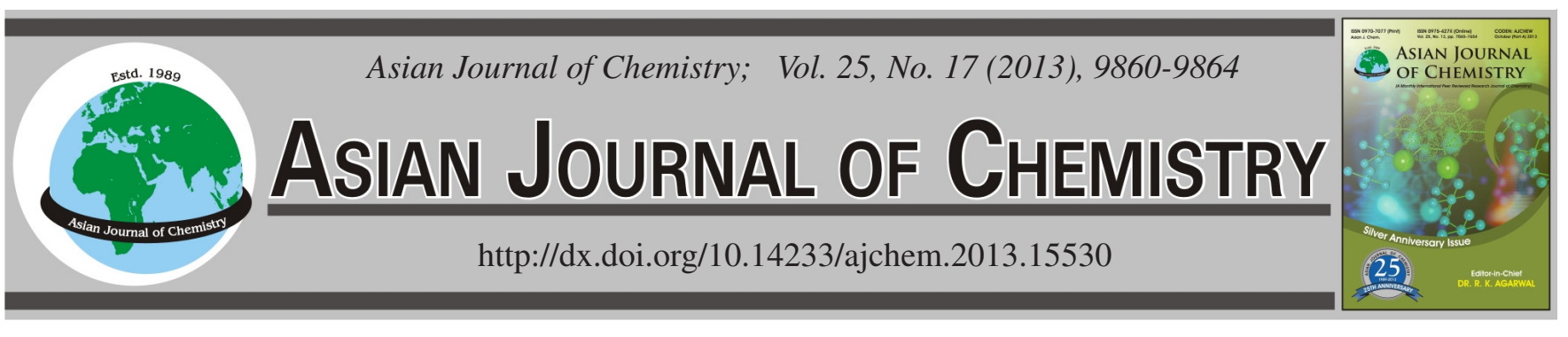

\title{
Statistical Classification of Cigarettes Using High Pressure Liquid Chromatograms of Cigarette Filter Tar as Fingerprint
}

\author{
Ayla Demirci ${ }^{1, *}$ and Meltem Ekiz ${ }^{2}$
}

${ }^{1}$ Department of Chemistry, Kirikkale University, Kirikkale, Turkey

${ }^{2}$ Department of Statistics, Gazi University, Ankara, Turkey

*Corresponding author: E-mail: aydem55@yahoo.com.tr; aydemirci55@gmail.com

\section{INTRODUCTION}

It is known that hundreds of organic and inorganic compounds well some of which are mutagenic, carcinogenic or toxic are present either in tobacco or produced during smoking. After smoking, some of them leave the cigarette with the smoke while some remain in filter tar. Since the smokers inhale the smoke into their body, most of the research focus on smoke analysis ${ }^{1}$. However, the filter (butt) is continuously in touch with the smoker's lips and consequently they have the chance that some hazardous compounds present in filter $\operatorname{tar}^{2,3}$, for instance benzo(a)pyrene ${ }^{4-7}$ may enter into the body. That means, filter residue analyses deserves equal attention as smoke analysis.

The quality control in tobacco industry has been performed either by feedback or feed forward by means of physical or chemical tests applied to either tobacco or manufactured tobacco products; for instance humidity, total alkaloids, total nitrogen, soluble material in ether, total filter tar, carbon dioxide in smoke, etc. On the other hand the constituents of smoke and residue in butt (filter) may be indicative for the quality and the type of the tobacco and the cigarette as well.

The fingerprint monitoring is another way of quality control of complex systems ${ }^{8-10}$. For instance Kosman and Lukco showed that the use of gas chromatography/atomic emission spectrometer (GC/AES) multielement simulated distillation for petroleum product fingerprinting ${ }^{8}$. The levels of chlorinated hydrocarbons in pine needles were used as fingerprints for the evaluation of the tropospheric contamination ${ }^{11}$.

Recently, several articles are reported on the chromatographic fingerprints ${ }^{12-22}$, Li et al. ${ }^{12}$ for instance, claimed that the binary chromatographic fingerprints, namely HPLC/DAD (diode array detector) fingerprint and GC/MS fingerprint are suitable for quality control of the total alkaloids. The chromatographic fingerprint was used by Burman and Albertsson ${ }^{13}$ as a tool for the classification and for predicting the degradation state of degradable polyethylene. The classification and the prediction models were obtained by multivariate analysis. Hajimahmoodi et al. ${ }^{14}$ reported a partial least square modelling and gas chromatographic fatty-acid fingerprints as a method for the simultaneous determination of cottonseed, olive, soy bean and sun flower oil mixtures. Permanyer et al. ${ }^{15}$ used gas chromatography fingerprints method to evaluate reservoir continuities and geochemical evolution of oils from individual reservoirs. Chen et al. ${ }^{16}$ developed a chemical fingerprint method using HPLC for investigating and demonstrating the variance of flavonoids among different origins of sea buckthorn berries. Both the correlation coefficient of similarity in 
chromatograms and the relative peak areas of 12 characteristic compounds in samples were calculated for quantitative expression of the HPLC fingerprints. Huang et al. ${ }^{22}$ showed that chromatographic fingerprints (GC/MS) combined with chemometrics could be used for quality control of coffee flavours. Xu et al. ${ }^{18}$ present an article on the pre-treatment of chromatographic fingerprints for the quality control of herbal medicines. Zhang et al. ${ }^{19}$ suggested that the analysis based on fingerprint characteristics of human skin emanation could provide useful and important clues to reveal biomarkers among the mixture of human skin emanations. They used SPME-GC/ MS sampling system. Yao et al. ${ }^{20}$ give a new algorithm of piecewise automated beam search for peak alignment of chromatographic fingerprints and have applied to an acetic acid-water solution containing aqueous extract of root and red rooted saliva and dalbergia wood. In forensic analysis and toxicology is often important to compare two or more samples with each other. Kuzmenko et al. ${ }^{23}$ used pyrolysis-chromatography. The pyrolized sample was directly sent to gas chromatography and pyrolized products were chromatographed and used as sample description. And also some articles appear on tobacco analysis. For instance Huang et al. ${ }^{21}$ gave a comparative study of the volatile components in cut tobacco with GC/MS and combined chemometrics methods.

As it was mentioned above hundreds of inorganic and organic compounds are present in filter tar. Determination of all the constituents in filter tar will give the most qualitative and quantitative information. However, this is time consuming and expensive.

We have shown here that liquid chromatographic data, namely chromatogram, can be used as a fingerprint of a cigarette. We also tried to show the classification of different cigarettes based on their chromatograms using a statistical approach. The method presented may also contribute the identification of the false cigarettes produced in illegal ways.

\section{EXPERIMENTAL}

Acetonitrile and $n$-hexane were HPLC grade and purchased from Merck (Darmstadt, Germany). A Millipore, ELIX 3 (USA) water purification system, was used to prepare the deionised water. Benzo(a)pyrene, at a concentration of $0.2 \mathrm{mg}$ $\mathrm{mL}^{-1}$ in dichloromethane was purchased from Accustandart, Inc. (USA).

The high pressure liquid chromatography (HPLC) system used was the Spectra System P 1500 (Thermo Separations Products, USA) equipped with an isocratic pump P 1500 and a Model 1000 time programmable wavelength UV spectrometer (Thermo Quest, USA). Data processing was conducted using a chromatographic Data System for WINDOWS NT and Thermo LC (IBM Infra 3600, Pentium III and Windows NT, Thermo Quest, USA).

A $10 \mu \mathrm{L}$ HPLC injector (SGE LC, 22 gauge, Supelco, USA) was used for injections onto HPLC. The sonic bath was from Bandelin Sonorex, (RK 51OH, Germany) and a magnetic stirrer (MS-H-Pro Magnetic Stirrer, Dragon Lab., USA) with a magnetic bar $(10 \mathrm{~mm}$ length and $3 \mathrm{~mm}$ diameter, Supelco, USA) was used for mixing the cigarette samples.
Five brands of cigarettes $(\mathrm{Cg} 1, \mathrm{Cg} 2, \mathrm{Cg} 3, \mathrm{Cg} 4$ and $\mathrm{Cg} 5)$ were bought randomly from the market, with the specifications given in Table-1. The analytical procedure described previously to determine benzo(a)pyrene ${ }^{4}$ in filter tar was also applied here. Five cigarettes of each type were smoked by means of a standard smoking machine. After smoking the filter was separated from the remaining of the cigarette. Then the covering filter paper was removed from the butt. The filter was first dissolved in $5 \mathrm{~mL}$ acetonitrile while being shaken 15 min. Then to the mixture $5 \mathrm{~mL}$ of $n$-hexane was added. After mixing thoroughly for five minutes the hexane layer was removed and evaporated to dryness. A $100 \mu \mathrm{L}$ of $n$-hexane was added to the residue and a $5 \mu \mathrm{L}$ portion was injected onto the HPLC. Total elution time was $25 \mathrm{~min}$.

\begin{tabular}{|c|c|c|c|}
\hline \multicolumn{4}{|c|}{$\begin{array}{c}\text { TABLE-1 } \\
\text { SOME PROPERTIES OF CIGARETTES } \\
\text { BOUGHT FROM THE MARKET }\end{array}$} \\
\hline & Tar (mg) & Nicotine (mg) & $\mathrm{CO}$ (mg) \\
\hline $\mathrm{Cg} 1$ & 10 & 0.8 & 10 \\
\hline $\mathrm{Cg} 2$ & 10 & 0.6 & 10 \\
\hline $\mathrm{Cg} 3$ & 10 & 0.8 & 10 \\
\hline $\mathrm{Cg} 4$ & 10 & 0.9 & 10 \\
\hline $\mathrm{Cg} 5$ & 8 & 0.7 & 9 \\
\hline
\end{tabular}

\section{RESULTS AND DISCUSSION}

Fig. 1 gives fingerprint chromatogram of cigarette filter $\operatorname{tar}(\mathrm{Cg} 3)$. The relative retention times of the most out coming peaks of the chromatogram were presented in Table-2. The relative retention times $(\mathrm{t})$ were calculated with respect to the retention time of benzo(a)pyrene. In the same table the corresponding peak heights (h) were also given. For the statistical evaluation four peaks heights with the relative retention times, $0.40,0.50,0.70,1.00$, were chosen from the chromatograms (same for all types of the cigarettes).

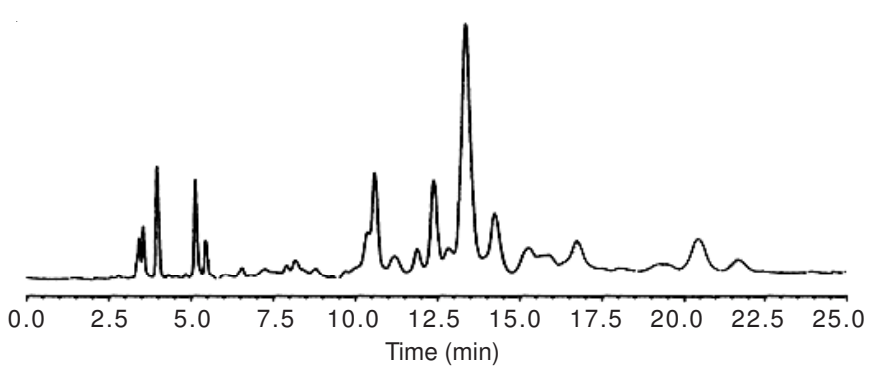

Fig. 1. Fingerprint chromatogram of cigarette $\mathrm{Cg} 3$

Statistical evaluation of the chromatograms: We introduced a Matlab computer program for the determination of the type of an unknown cigarette butt from the HPLC chromatogram of its filter tar. The program is based on the method developed by Anderson for classifying problems ${ }^{24}$.

Suppose we have two multivariate normal distributed populations, namely, $\pi_{\mathrm{Cg} 1}$ and $\pi_{\mathrm{Cg} 2}(\mathrm{Cg} 1=$ Cigarette $1, \mathrm{Cg} 2=$ Cigarette2) and a sample (chromatogram), from each of these

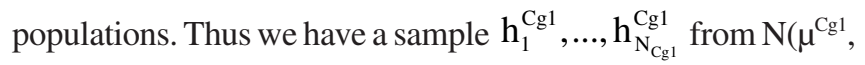
$\Sigma$ ) and a sample $\mathrm{h}_{1}^{\mathrm{Cg} 2}, \ldots, \mathrm{h}_{\mathrm{N}_{\mathrm{Cg} 2}}^{\mathrm{Cg} 2}$ from $\mathrm{N}\left(\mu^{\mathrm{Cg} 2}, \Sigma\right)$. Where, $\mathrm{h}_{\mathrm{j}}{ }^{\mathrm{i}}$ (i $=\mathrm{Cg} 1, \mathrm{Cg} 2$ and $\mathrm{j}=1, \ldots, \mathrm{N}_{\mathrm{i}}$ ) is the peak height of the $\mathrm{j}$-th 


\begin{tabular}{|c|c|c|c|c|c|c|c|c|c|}
\hline \multicolumn{10}{|c|}{$\begin{array}{c}\text { TABLE-2 } \\
\text { RELATIVE RETENTION TIMES AND THE NORMALIZED PEAK HEIGTHS OF CIGARETTE Cg3 }\end{array}$} \\
\hline \multicolumn{2}{|c|}{ Cg3-1 } & \multicolumn{2}{|c|}{ Cg3-2 } & \multicolumn{2}{|c|}{$\mathrm{Cg} 3-3$} & \multicolumn{2}{|c|}{$\mathrm{Cg} 3-4$} & \multicolumn{2}{|c|}{$\mathrm{Cg} 3-5$} \\
\hline $\mathrm{t}$ & $\mathrm{h}$ & $\mathrm{t}$ & $\mathrm{h}$ & $\mathrm{t}$ & $\mathrm{h}$ & $\mathrm{t}$ & $\mathrm{h}$ & $\mathrm{t}$ & $\mathrm{h}$ \\
\hline 0.379 & 0.54 & 0.382 & 0.66 & 0.382 & 0.47 & 0.381 & 0.42 & 0.356 & 0.47 \\
\hline 0.424 & 0.28 & 0.426 & 0.26 & 0.427 & 0.28 & 0.426 & 0.20 & 0.394 & 0.41 \\
\hline 0.468 & 0.70 & 0.471 & 1.14 & 0.472 & 0.69 & 0.471 & 0.66 & 0.429 & 0.55 \\
\hline 0.486 & 0.59 & 0.488 & 0.98 & 0.489 & 1.21 & 0.488 & 1.11 & 0.443 & 0.75 \\
\hline 0.563 & 0.36 & 0.567 & 0.28 & 0.566 & 0.22 & 0.564 & 0.30 & 0.526 & 0.28 \\
\hline 0.645 & 1.60 & 0.650 & 1.80 & 0.647 & 1.12 & 0.647 & 1.38 & 0.562 & 1.82 \\
\hline 0.660 & 2.90 & 0.664 & 2.85 & 0.664 & 1.69 & 0.663 & 2.64 & 0.574 & 4.10 \\
\hline 0.686 & 1.37 & 0.690 & 1.44 & 0.689 & 1.50 & 0.688 & 1.21 & 0.606 & 0.84 \\
\hline 0.750 & 1.30 & 0.756 & 1.26 & 0.753 & 0.50 & 0.753 & 0.81 & 0.642 & 1.11 \\
\hline 0.780 & 2.85 & 0.785 & 3.92 & 0.784 & 1.62 & 0.784 & 2.67 & 0.669 & 3.75 \\
\hline 0.813 & 1.06 & 0.813 & 1.44 & 0.817 & 0.62 & 0.816 & 2.34 & 0.693 & 1.10 \\
\hline 0.848 & 7.36 & 0.852 & 5.88 & 0.852 & 3.82 & 0.851 & 6.10 & 0.721 & 9.87 \\
\hline 0.912 & 2.28 & 0.918 & 1.49 & 0.919 & 1.05 & 0.918 & 1.43 & 0.768 & 2.41 \\
\hline 0.990 & 0.82 & 0.994 & 0.83 & 0.994 & 0.52 & 0.994 & 0.66 & 0.823 & 1.03 \\
\hline 1.033 & 1.79 & 1.036 & 0.46 & 1.038 & 0.17 & 1.031 & 0.44 & 0.858 & 0.72 \\
\hline 1.103 & 1.08 & 1.105 & 0.95 & 1.104 & 0.34 & 1.106 & 0.67 & 0.904 & 1.20 \\
\hline
\end{tabular}

cigarette in the $\mathrm{i}$-th population, $\mu^{(\mathrm{Cg} 1)^{\prime}}=\left(\mu_{1}{ }^{\mathrm{Cg} 1}, \ldots, \mu_{\mathrm{p}}^{\mathrm{Cg} 1}\right)$ and $\mu^{(\mathrm{Cg} 2)^{\prime}}=\left(\mu_{1}^{\mathrm{Cg} 2}, \ldots, \mu_{\mathrm{p}}^{\mathrm{Cg} 2}\right)$ are the vectors of means, $\mathrm{p}$ is the number of the selected relative retention times, $\Sigma$ is the matrix of variances and covariances and $\mathrm{N}_{\mathrm{i}}$ is the sample size of the $\mathrm{i}$-th population. Then we want to classify a new sample (an unknown cigarette) into one of these populations. This sample can be thought as a point in a p-dimensional space. The space is assumed to be divided into two regions. If the sample falls in the region $R_{C g 1}$, it is classified as coming from population $\pi_{\mathrm{Cg} 1}$ and if it falls in the region $\mathrm{R}_{\mathrm{Cg} 2}$, it is classified as coming from $\pi_{\mathrm{Cg} 2}$. In order to classify the unknown cigarette into one of these regions, we need the peak heights vector $h^{\prime}=\left(h_{1}, \ldots\right.$, $\mathrm{h}_{\mathrm{p}}$ ).

Let the density of population $\pi_{\mathrm{Cg} 1}$ be $\mathrm{p}_{\mathrm{Cg} 1}(\mathrm{~h})$ and that of $\pi_{\mathrm{Cg} 2}$ be $\mathrm{p}_{\mathrm{Cg} 2}(\mathrm{~h})$. So, the probability density functions for $\mathrm{Cg} 1$ and $\mathrm{Cg} 2$ are

$$
\mathrm{p}_{\mathrm{Cg} 1}(\mathrm{~h})=\frac{1}{(2 \pi)^{\frac{1}{2} \mathrm{p}}|\Sigma|^{\frac{1}{2}}} \exp \left[-\frac{1}{2}\left(\mathrm{~h}-\mu^{(\mathrm{Cg} 1)}\right)^{\prime} \Sigma^{-1}\left(\mathrm{~h}-\mu^{(\mathrm{Cg} 1)}\right)\right]
$$

and

$$
\mathrm{p}_{\mathrm{Cg} 2}(\mathrm{~h})=\frac{1}{(2 \pi)^{\frac{1}{2} \mathrm{p}}|\Sigma|^{\frac{1}{2}}} \exp \left[-\frac{1}{2}\left(\mathrm{~h}-\mu^{(\mathrm{Cg} 2)}\right)^{\prime} \Sigma^{-1}\left(\mathrm{~h}-\mu^{(\mathrm{Cg} 2)}\right)\right] .
$$

The ratio of densities is

$$
\begin{aligned}
\mathrm{p}= & \frac{\mathrm{p}_{\mathrm{cg} 1}(\mathrm{~h})}{\mathrm{p}_{\mathrm{cg} 2}(\mathrm{~h})}=\exp \left\{-\frac{1}{2}\left[\left(\mathrm{~h}-\mu^{(\mathrm{gg} 1)}\right)^{\prime} \Sigma^{-1}\left(\mathrm{~h}-\mu^{(\mathrm{gg} 1)}\right)-\left(\mathrm{h}-\mu^{(\mathrm{Cg} 2)}\right)^{\prime} \Sigma^{-1}\left(\mathrm{~h}-\mu^{(\mathrm{g} 2)}\right)\right]\right\} . \\
& \text { If } \mathrm{p} \geq 1,
\end{aligned}
$$

then the region of classifying the unknown cigarette into $\pi_{\mathrm{Cg} 1}$ will be $\mathrm{R}_{\mathrm{Cg} 1}$. If $\mathrm{p}<1$ the cigarette is classified into region $\mathrm{R}_{\mathrm{Cg} 2}$. The two multivariate distributions explained above can be applied to higher number of cigarettes, say 5 as in our case. In this case, the space is divided into 5 regions.

To proceed further we can take the logarithm of inequality (eqn. 3) since it is increasing monotonically:

$$
-\frac{1}{2}\left[\left(\mathrm{~h}-\mu^{(\mathrm{Cg} 1)}\right)^{\prime} \Sigma^{-1}\left(\mathrm{~h}-\mu^{(\mathrm{Cg} 1)}\right)-\left(\mathrm{h}-\mu^{(\mathrm{Cg} 2)}\right)^{\prime} \Sigma^{-1}\left(\mathrm{~h}-\mu^{(\mathrm{Cg} 2)}\right)\right] \geq 0 .
$$

By rearranging the terms on the left hand side the wellknown discriminate function,

$$
\mathrm{h}^{\prime} \Sigma^{-1}\left(\mu^{(\mathrm{Cg} 1)}-\mu^{(\mathrm{Cg} 2)}\right)-\frac{1}{2}\left(\mu^{(\mathrm{Cg} 1)}+\mu^{(\mathrm{Cg} 2)}\right)^{\prime} \Sigma^{-1}\left(\mu^{(\mathrm{Cg} 1)}-\mu^{(\mathrm{Cg} 2)}\right)
$$

will be obtained. The program given in Appendix is based on this function and applied to 5 cigarettes. In this program $\mathrm{m}$, the number of populations $(\mathrm{Cg} 1, \mathrm{Cg} 2, \mathrm{Cg} 3, \mathrm{Cg} 4, \mathrm{Cg} 5)$, is 5 and $\mathrm{p}$, selected relative times, $\mathrm{t}=0.40,0.50,0.70,1.00$ of each type, is 4 . The estimation of $\mu_{\mathrm{h}}{ }^{(\mathrm{i})}$ and $\Sigma$ are calculated from equations given below:

$$
\overline{\mathrm{h}}^{(\mathrm{i})}=\sum_{\mathrm{j}=1}^{\mathrm{N}_{\mathrm{i}}} \mathrm{h}_{\mathrm{j}}^{(\mathrm{i})} / \mathrm{N}_{\mathrm{i}}
$$

and

$$
\mathrm{S}=\frac{1}{\sum_{\mathrm{i}=1}^{\mathrm{m}} \mathrm{N}_{\mathrm{i}}-\mathrm{m}} \sum_{\mathrm{i}=1}^{\mathrm{m}} \sum_{\mathrm{j}=1}^{\mathrm{N}_{\mathrm{i}}}\left(\mathrm{h}_{\mathrm{j}}^{(\mathrm{i})}-\overline{\mathrm{h}}^{(\mathrm{i})}\right)\left(\mathrm{h}_{\mathrm{j}}^{(\mathrm{i})}-\overline{\mathrm{h}}^{(\mathrm{i})}\right)^{\prime}
$$

where $\mathrm{N}_{\mathrm{i}}=5$.

Appendix: The program:

$\mathrm{h}=[0.06,0.15,0.31,0.10]$

$\mathrm{Cg} 1=[2.14,3.04,1.72,0.29 ; 3.68,4.11,3.49,0.45 ; 2.55,2.99$, $3.36,0.30 ; 3.31,4.09,2.15,0.69 ; 2.42,2.83,3.70,0.27]$

$\mathrm{Cg} 2=[0.23,0.29,0.11,0.09 ; 0.17,0.16,0.10,0.044 ; 0.16$, $0.14,0.025,0.074 ; 0.32,0.28,0.15,0.13$;

$0.21,0.12,0.073,0.11]$

Cg3 $=[0.54,0.59,1.37,1.08 ; 0.66,0.98,1.44,0.95 ; 0.47,1.21,1.50$, $0.34 ; 0.42,1.11,1.21,0.67 ; 0.47,0.28,1.10,1.27]$

$\mathrm{Cg} 4=[0,0.42,0.14,0 ; 0.024,0.22,0.24,0.16 ; 0,0.13,0.28,0.082$; $0.04,0.18,0.28,0.13 ; 0.027,0.26$,

$0.24,0.076]$

$\mathrm{Cg} 5=[4.74,3.70,0.85,0.76 ; 3.66,4.55,3.54,3.91 ; 4.27,6.09$, $0.76,4.33 ; 3.57,1.50,0.43,0.74 ; 4.74,3.70,0.85,0.76]$

top $1=0$;

top $2=0$

top $3=0$;

top4 $=0$

top $5=0$;

h1=mean $(\mathrm{Cg} 1)$ 
$\mathrm{h} 2=$ mean $(\mathrm{Cg} 2)$

h3=mean $(\mathrm{Cg} 3)$

h4=mean (Cg4)

h5=mean $(\mathrm{Cg} 5)$

for $\mathrm{I}=1: 5$

$\mathrm{y} 1=\operatorname{Cg} 1(\mathrm{i},:)$;

$\mathrm{t} 1=(\mathrm{y} 1-\mathrm{h} 1)^{\prime} *(\mathrm{y} 1-\mathrm{h} 1)$

top $1=$ top $1+\mathrm{t} 1$;

$\mathrm{y} 2=\mathrm{Cg} 2(\mathrm{i},:)$;

$\mathrm{t} 2=(\mathrm{y} 2-\mathrm{h} 2)^{\prime} *(\mathrm{y} 2-\mathrm{h} 2)$;

top2=top2+t2;

y3=Cg3(i,:);

t3 $=(y 3-h 3)^{\prime} *(y 3-h 3)$;

top3=top3+t3;

y4=Cg4 (i,:);

$\mathrm{t} 4=(\mathrm{y} 4-\mathrm{h} 4)^{\prime} *(\mathrm{y} 4-\mathrm{h} 4)$;

top4=top4+t4;

y5=Cg5(i,:);

$\mathrm{t} 5=(\mathrm{y} 5-\mathrm{h} 5)^{\prime} *(\mathrm{y} 5-\mathrm{h} 5)$;

top5=top5+t5;

end

$\mathrm{C}=($ top1+top2+top3+top4+top5)/ (20-5)

B12 $=(\mathrm{h}-(1 / 2) *(\mathrm{~h} 1+\mathrm{h} 2)) * \operatorname{inv}(\mathrm{C}) *(\mathrm{~h} 1-\mathrm{h} 2)^{\prime}$;

B13 $=(\mathrm{h}-(1 / 2) *(\mathrm{~h} 1+\mathrm{h} 3)) * \operatorname{inv}(\mathrm{C}) *(\mathrm{~h} 1-\mathrm{h} 3)^{\prime}$;

B14= (h- $(1 / 2) *(h 1+h 4)) * \operatorname{inv}(\mathrm{C}) *(\mathrm{~h} 1-\mathrm{h} 4))^{\prime}$;

$\mathrm{B} 15=(\mathrm{h}-(1 / 2) *(\mathrm{~h} 1+\mathrm{h} 5)) * \operatorname{inv}(\mathrm{C}) *(\mathrm{~h} 1-\mathrm{h} 5))^{\prime}$;

$\mathrm{K} 1=\mathrm{abs}(\mathrm{B} 12)+\mathrm{abs}(\mathrm{B} 13)+\mathrm{abs}(\mathrm{B} 14)+\mathrm{abs}(\mathrm{B} 15)$;

$\mathrm{D} 1=\mathrm{B} 12+\mathrm{B} 13+\mathrm{B} 14+\mathrm{B} 15$;

$\mathrm{B} 21=(\mathrm{h}-(1 / 2) *(\mathrm{~h} 2+\mathrm{h} 1)) * \operatorname{inv}(\mathrm{C}) *(\mathrm{~h} 2-\mathrm{h} 1) '$;

B23 $=(\mathrm{h}-(1 / 2) *(\mathrm{~h} 2+\mathrm{h} 3)) * \operatorname{inv}(\mathrm{C}) *(\mathrm{~h} 2-\mathrm{h} 3)$ ';

B24 $=(\mathrm{h}-(1 / 2) *(\mathrm{~h} 2+\mathrm{h} 4)) * \operatorname{inv}(\mathrm{C}) *(\mathrm{~h} 2-\mathrm{h} 4)^{\prime}$;

$\mathrm{B} 25=(\mathrm{h}-(1 / 2) *(\mathrm{~h} 2+\mathrm{h} 5)) * \operatorname{inv}(\mathrm{C}) *(\mathrm{~h} 2-\mathrm{h} 5)^{\prime}$;

$\mathrm{K} 2=\mathrm{abs}(\mathrm{B} 21)+\mathrm{abs}(\mathrm{B} 23)+\mathrm{abs}(\mathrm{B} 24)+\mathrm{abs}(\mathrm{B} 25)$;

$\mathrm{D} 2=\mathrm{B} 21+\mathrm{B} 23+\mathrm{B} 24+\mathrm{B} 25$;

$\mathrm{B} 31=(\mathrm{h}-(1 / 2) *(\mathrm{~h} 3+\mathrm{h} 1)) * \operatorname{inv}(\mathrm{C}) *(\mathrm{~h} 3-\mathrm{h} 1))^{\prime}$;

B32 $=(\mathrm{h}-(1 / 2) *(\mathrm{~h} 3+\mathrm{h} 2)) * \operatorname{inv}(\mathrm{C}) *(\mathrm{~h} 3-\mathrm{h} 2))^{\prime}$;

B34 $=(\mathrm{h}-(1 / 2) *(\mathrm{~h} 3+\mathrm{h} 4)) * \operatorname{inv}(\mathrm{C}) *(\mathrm{~h} 3-\mathrm{h} 4))^{\prime}$;

B35 $=(\mathrm{h}-(1 / 2) *(\mathrm{~h} 3+\mathrm{h} 5)) * \operatorname{inv}(\mathrm{C}) *(\mathrm{~h} 3-\mathrm{h} 5)^{\prime}$;

$\mathrm{K} 3=\mathrm{abs}(\mathrm{B} 31)+\mathrm{abs}(\mathrm{B} 32)+\mathrm{abs}(\mathrm{B} 34)+\mathrm{abs}(\mathrm{B} 35)$;

$\mathrm{D} 3=\mathrm{B} 31+\mathrm{B} 32+\mathrm{B} 34+\mathrm{B} 35$;

B41 $=(\mathrm{h}-(1 / 2) *(\mathrm{~h} 4+\mathrm{h} 1)) * \operatorname{inv}(\mathrm{C}) *(\mathrm{~h} 4-\mathrm{h} 1)^{\prime}$;

B42 $=(\mathrm{h}-(1 / 2) *(\mathrm{~h} 4+\mathrm{h} 2)) * \operatorname{inv}(\mathrm{C}) *(\mathrm{~h} 4-\mathrm{h} 2){ }^{\prime}$;

B43 $=(\mathrm{h}-(1 / 2) *(\mathrm{~h} 4+\mathrm{h} 3)) * \operatorname{inv}(\mathrm{C}) *(\mathrm{~h} 4-\mathrm{h} 3)^{\prime}$;

$\mathrm{B} 45=(\mathrm{h}-(1 / 2) *(\mathrm{~h} 4+\mathrm{h} 5)) * \operatorname{inv}(\mathrm{C}) *(\mathrm{~h} 4-\mathrm{h} 5)^{\prime}$;

$\mathrm{K} 4=\mathrm{abs}(\mathrm{B} 41)+\mathrm{abs}(\mathrm{B} 42)+\mathrm{abs}(\mathrm{B} 43)+\mathrm{abs}(\mathrm{B} 45)$;

$\mathrm{D} 4=\mathrm{B} 41+\mathrm{B} 42+\mathrm{B} 43+\mathrm{B} 45$;

$\mathrm{B} 51=(\mathrm{h}-(1 / 2) *(\mathrm{~h} 5+\mathrm{h} 1)) * \operatorname{inv}(\mathrm{C}) *(\mathrm{~h} 5-\mathrm{h} 1))^{\prime}$;

B52 $=(\mathrm{h}-(1 / 2) *(\mathrm{~h} 5+\mathrm{h} 2)) * \operatorname{inv}(\mathrm{C}) *(\mathrm{~h} 5-\mathrm{h} 2)^{\prime}$;

$\mathrm{B} 53=(\mathrm{h}-(1 / 2) *(\mathrm{~h} 5+\mathrm{h} 3)) * \operatorname{inv}(\mathrm{C}) *(\mathrm{~h} 5-\mathrm{h} 3))^{\prime}$;

B54 $=(\mathrm{h}-(1 / 2) *(\mathrm{~h} 5+\mathrm{h} 4)) * \operatorname{inv}(\mathrm{C}) *(\mathrm{~h} 5-\mathrm{h} 4)^{\prime}$;

$\mathrm{K} 5=\mathrm{abs}(\mathrm{B} 51)+\mathrm{abs}(\mathrm{B} 52)+\mathrm{abs}$ (B53) +abs (B54);

$\mathrm{D} 5=\mathrm{B} 51+\mathrm{B} 52+\mathrm{B} 53+\mathrm{B} 54$;

If $\mathrm{K} 1==\mathrm{D} 1$ 'The butt of the tobacco is $\mathrm{Cg} 1$.'

End

If $\mathrm{K} 2==\mathrm{D} 2$ 'The butt of the tobacco is $\mathrm{Cg} 2$.'

End

If $\mathrm{K} 3==\mathrm{D} 3$ 'The butt of the tobacco is $\mathrm{Cg} 3$.'

End
If $\mathrm{K} 4==\mathrm{D} 4$ 'The butt of the tobacco is Cg4.'

End

If $\mathrm{K} 5==\mathrm{D} 5$ 'The butt of the tobacco is Cg5.'

End

\%in real $\mathrm{Cg} 1$;

alpha1 $=(\mathrm{h} 1-\mathrm{h} 2) * \operatorname{inv}(\mathrm{C}) *(\mathrm{~h} 1-\mathrm{h} 2))^{\prime}$;

P12 = normcdf $(-($ sqrt (alpha1)/2), alpha1/2, alpha1)

alpha1 $=($ h1-h3 $) * \operatorname{inv}(\mathrm{C}) *(\mathrm{~h} 1-\mathrm{h} 3)$ ';

P13 = normedf $(-($ sqrt (alpha1)/2), alpha1/2, alpha1)

alpha1 $=($ h1-h4 $) * \operatorname{inv}(\mathrm{C}) *(\mathrm{~h} 1-\mathrm{h} 4)$ ';

P14 = normcdf $(-($ sqrt $($ alpha1 $) / 2)$, alpha1/2, alpha1 $)$

alpha1 $=(\mathrm{h} 1-\mathrm{h} 5) * \operatorname{inv}(\mathrm{C}) *(\mathrm{~h} 1-\mathrm{h} 5)^{\prime}$;

$\mathrm{P} 15=\operatorname{normcdf}(-(\operatorname{sqrt}($ alpha1 $) / 2)$, alpha1/2,alpha1 $)$

$\%$ In real $\mathrm{Cg} 2$ :

alpha1 $=($ h2-h3 $) * \operatorname{inv}(\mathrm{C}) *(\mathrm{~h} 2-\mathrm{h} 3)^{\prime}$;

P23 = normcdf (-(sqrt (alpha1)/2), alpha1/2, alpha1)

alpha1 $=(\mathrm{h} 2-\mathrm{h} 4) * \operatorname{inv}(\mathrm{C}) *(\mathrm{~h} 2-\mathrm{h} 4)$ ';

P24 = normcdf $(-($ sqrt $($ alpha1 $) / 2)$, alpha1/2, alpha1)

alpha1 $=(\mathrm{h} 2-\mathrm{h} 5) * \operatorname{inv}(\mathrm{C}) *(\mathrm{~h} 2-\mathrm{h} 5)^{\prime}$;

P25 = normcdf $(-($ sqrt $($ alpha1 $) / 2)$, alpha1/2, alpha1)

\%In real Cg3:

alpha1 $=(\mathrm{h} 3-\mathrm{h} 4) * \operatorname{inv}(\mathrm{C}) *(\mathrm{~h} 3-\mathrm{h} 4)^{\prime}$;

P34 = normcdf $(-($ sqrt $($ alpha1 $) / 2)$, alpha1/2, alpha1)

alpha1 $=($ h3-h5 $) * \operatorname{inv}(\mathrm{C}) *(\mathrm{~h} 3-\mathrm{h} 5)$ ';

P35 = normcdf $(-($ sqrt $($ alpha1 $) / 2)$, alpha1/2, alpha1)

$\%$ In real $\mathrm{Cg} 4$ :

alpha1 $=(\mathrm{h} 4-\mathrm{h} 5) * \operatorname{inv}(\mathrm{C}) *(\mathrm{~h} 4-\mathrm{h} 5))^{\prime}$;

P45 = normcdf (-(sqrt (alpha1)/2), alpha1/2, alpha1)

The HPLC chromatograms of different cigarettes obtained under certain conditions are quite specific. The fingerprint chromatogram of $\mathrm{Cg} 3$ was shown in Fig. 1. They can be used as fingerprints for the characterization of the cigarettes. Although by GC/MS and HPLC/MS systems one can get more valuable qualitative and quantitative data, not many laboratories have these expensive systems. Besides, highly qualified operators are needed to use these sophisticated systems. The proposed method here, to monitor the quality of tobacco and the tobacco products, is simple, not expensive and can be performed in a relatively short time.

The classification of the cigarettes produced by the manufactures is another objective of our work. This is certainly not a simple work. The production parameters of the factories may change from time to time, so the fingerprints. The fingerprint data were obtained either by following certain selected compounds in a complex matrix or, as in our case, by using a certain pattern in the target sample. Just to show the applicability of chromatographic fingerprinting we took five different randomly selected cigarettes. Each one of one type was bought at a different time.

The reproducibility of the peak heights were about $10 \%$. Misclassification probabilities of an unknown cigarette in other regions were calculated using the equations introduced by Anderson $^{24}$. These probabilities are given in Table-3. As shown in Table-3, the misclassification probabilities of an unknown cigarette lie around 0.25 which is quiet reasonable. For instance, the probability of misclassifying $\mathrm{Cg} 4$ as $\mathrm{Cg} 1$ is $28.54 \%$ and $\mathrm{Cg} 5$ as $\mathrm{Cg} 3$ is $29.08 \%$. 


\begin{tabular}{|c|c|c|c|c|c|}
\hline \multicolumn{6}{|c|}{$\begin{array}{c}\text { TABLE-3 } \\
\text { MISCLASSIFICATION PROBABILITIES OF } \\
\text { AN UNKNOWN CIGARETTE }\end{array}$} \\
\hline & $\mathrm{Cg} 1$ & $\mathrm{Cg} 2$ & $\mathrm{Cg} 3$ & $\mathrm{Cg} 4$ & $\mathrm{Cg} 5$ \\
\hline $\mathrm{Cg} 1$ & - & 0.2845 & 0.2794 & 0.2854 & 0.2851 \\
\hline $\mathrm{Cg} 2$ & 0.2845 & - & 0.2196 & 0.1298 & 0.2926 \\
\hline $\mathrm{Cg} 3$ & 0.2794 & 0.2196 & - & 0.2334 & 0.2908 \\
\hline $\mathrm{Cg} 4$ & 0.2854 & 0.1298 & 0.2334 & - & 0.2935 \\
\hline Cg5 & 0.2851 & 0.2926 & 0.2908 & 0.2935 & - \\
\hline
\end{tabular}

The program can be extended to apply to a larger range of cigarettes. In that case number of relative retention times, not exceeding the sample sizes, must be higher to reach a reasonable classification.

\section{Conclusion}

Herewith we have introduced a computer program following an analytical procedure to show that liquid chromatograms could be used as fingerprints to characterize and classify cigarettes. This may contribute monitoring the factory defined quality of cigarettes. We do not present a method to be use for comparing factory product with a standard, such as Kentucky reference cigarette KY2R4F or Canadian Industry Monitor 7 reference cigarette. We just give a methodology that a manufacturer could see the deviations in his products during production. If the production variables are changed then certainly the fingerprint chromatograms will change.

Our main assumption is that the product of a factory is of a definite quality. Instead of carrying out the whole physical and chemical analysis, including GC/MS and HPLC/MS analysis, the manufactures can use our method to see the product is of required (defined) quality, in a very short time at a reasonable cost. If the standard smoking or the standards of the factory are changed the method is still applicable.

The proposed method may also contribute the identification of the false cigarettes produced in illegal ways. Having the chromatographic pattern (fingerprint) of the cigarette filter tar, one could easily differentiate the false one.

In summary we have showed that the liquid chromatogram of a cigarette filter tar can be used as a fingerprint of a cigarette.

\section{ACKNOWLEDGEMENTS}

The authors thanks to the Turkish Tekel Institute, Istanbul, for using their smoking machine.

\section{REFERENCES}

1. H. Lu and L. Zhu, J. Hazard. Materials, 139, 193 (2007).

2. A. Demirci and B. Morkan, Asian J. Chem., 25, 6531 (2013).

3. C.R. Green, F.W. Conrad, K.A. Bridle and M.F. Borgerding, Beitr. Tabakforsch. Int., 13, 11 (1985).

4. F. Aygün, A. Demirci and M. Özcimder, J. Agric. Food Chem., 44, 1488 (1996).

5. S.F. Aygün, J. Sep. Sci., 28, 2370 (2005).

6. A. Demirci and E. Alver, J. Liq. Chromatogr. Rel. Technol., 36, 628 (2013).

7. A. Demirci, Ph.D. Thesis, A Study on the Problems Encountered During the Analysis of Polycyclic Aromatic Hydrocarbons by Means of High Pressure Liquid Chromatography, Ondokuz Mayis University, Turkey (2000).

8. J.J. Kosman and R.G. Lukco, J. Chromatogr. Sci., 31, 88 (1993).

9. N.B. Vogt and C.E. Sjoegren, Anal. Chim. Acta, 222, 135 (1989).

10. S.A. Vandergrift and D.H. Kampbell, J. Chromatogr. Sci., 26, 566 (1988).

11. D. Calamari, P. Tremolada, A. Di Guardo and M. Vighi, Environ. Sci. Technol., 28, 429 (1994).

12. Y. Li, Z. Hu and L. He, J. Pharm. Biomed. Anal., 43, 1667 (2007).

13. L. Burman and A.C. Albertsson, Polym. Degrad. Stab., 89, 50 (2005).

14. M. Hajimahmoodi, Y. Vander Heyden, N. Sadeghi, B. Jannat, M.R. Oveisi and S. Shahbazian, Talanta, 66, 1108 (2005).

15. A. Permanyer, L. Douifi, A. Lahcini, J. Lamontagne and J. Kister, Fuel, 81, 861 (2002).

16. C. Chen, H. Zhang, W. Xiao, Z.P. Yong and N. Bai, J. Chromatogr. A, 1154, 250 (2007).

17. U. Siripatrawan and B.R. Harte, Anal. Chim. Acta, 581, 63 (2007).

18. C.J. Xu, Y.Z. Liang, F.T. Chau and Y. van der Heyden, J. Chromatogr. A, 1134, 253 (2006).

19. Z.M. Zhang, J.J. Cai, G.H. Ruan and G.K. Li, J. Chromatogr. B, 822, 244 (2005)

20. W. Yao, X. Yin and Y. Hu, J. Chromatogr. A, 1160, 254 (2007).

21. L.F. Huang, K.J. Zhong, X.J. Sun, M.J. Wu, K.L. Huang, Y.Z. Liang, F.Q. Guo and Y.W. Li, Anal. Chim. Acta, 575, 236 (2006).

22. L.F. Huang, M.J. Wu, K.J. Zhong, X.J. Sun, Y.Z. Liang, Y.H. Dai, K.L. Huang and F.Q. Guo, Anal. Chim. Acta, 588, 216 (2007).

23. T.E. Kuzmenko, A.L. Samusenko and V.P. Uralets and R.V. Golovnya, J. High Resol. Chromatogr., 2, 43 (1979).

24. T.W. Anderson, An Introduction to Multivariate Statistical Analysis, John Wiley \& Sons, Inc. (1958). 